\title{
Urothelial carcinoma in remnant ureter in kidney transplanted patient after bilateral native nephrectomy - A rare case and literature review
}

\author{
Angel Elenkov ${ }^{1}$, Plamen Dimitrov ${ }^{1}$, Peter Simeonov' ${ }^{1}$, Peter Panchev ${ }^{1}$ \\ ${ }^{1}$ Medical University Sofia, Bulgaria \\ Elenkov A, Dimitrov P, Simeonov P, Panchev P. Urothelial carcinoma in remnant ureter in kidney transplanted patient after bilateral native \\ nephrectomy - A rare case and literature review. J Pre-Clin Clin Res. 2016; 10(2): 131-132. doi: 10.5604/18982395.1227571
}

\section{Abstract}

The occurrence of primary ureteral carcinoma of the remnant ureter after nephrectomy for benign disease is very rare, and such cases in a kidney transplanted patient are even rarer. The case of a 62-year-old female patient is presented who had end stage autosomal dominant polycystic kidney disease and in 1991 underwent cadaveric kidney transplantation. Immunosuppression therapy was maintained with evorolimus and prednisolone. Normal serum creatinine levels were maintained and no signs of allograft rejection were detected. In 2010, the patient developed intermittent macroscopic haematuria and was admitted for further evaluation. Computer tomography, cystoscopy, laboratory tests and urine cytology were performed and no apparent reason for the haematuria was found. After more episodes of uncontrollable haematuria, in 2011 she underwent bilateral nephrectomy of her native kidneys. In 2015, after another episode of haematuria, a CT was performed on the patient. She was diagnosed with a solid enhancing mass in the right ureteral stump. Ureterectomy with bladder cuff excision was performed with lower midline laparotomy. The specimen was verified as high grade urothelial carcinoma, in stage T1 according to the 2004 WHO grading system. To the best of the authors' knowledge, this is first case in the availabe literature of the occurrence of transitional cell carcinoma developing in the remnant ureter in a kidney transplanted patient after bilateral prophylactic nephrectomy for uncontrollable haematuria - 24 years after transplantation.

\section{Key words}

urothelial carcinoma, remnant, ureter, kidney transplant

\section{INTRODUCTION}

Autosomal dominant polycystic kidney disease (ADPKD) is the most common genetic disorder leading to end-stage renal failure and the disease in kidney transplanted patients. It is also associated with cases of refractory hypertension, pain or uncontrollable haematuria. This is why prophylactic native nephrectomy is performed [1]. The occurrence of primary ureteral carcinoma of the remnant ureter after nephrectomy for benign disease is very rare [2]. This is why the remaining ureteral stump does not usually receive any additional attention after nephrectomy for non-cancer related reasons.

We report a case of transitional cell carcinoma developed in the remnant ureter in a kidney transplanted patient after bilateral prophylactic nephrectomy for uncontrollable haematuria occuring 24 years after transplantation.

\section{CASE REPORT}

The case is presented of a 62-year-old female patient who underwent cadaveric kidney transplantation in 1991 because of end stage ADPKD. Immunosuppression therapy was maintained with evorolimus and prednisolone. Normal serum creatinine levels were maintained and no signs of allograft rejection were detected. In 2010, the patient developed intermittent macroscopic haematuria and was admitted

Address for correspondence: Angel Elenkov, Medical University Sofia Obelia 2 bl.214 ap.56, 1326 Sofia, Bulgaria

E-mail: a.elenkov@abv.bg

Received: 07 January 2016; accepted: 10 November 2016 for further evaluation. Computer tomography, cystoscopy, laboratory tests and urine cytology were performed and no apparent reason for the haematuria was found. After conservative treatment the patient was discharged. After some intermittent episodes of macroscopic haematuria in 2011, the patient was admitted again with anaemia, syncope and gross haematuria, which necessitated blood transfusion. CT, urine cytology and cystoscopy again revealed no apparent reason for the condition. The situation was discussed with the patient and a decision for bilateral native nephrectomy was taken, by the responsible physicians and the patient. Nephrectomy was performed in March and July 2011 for the right and left kidneys, respectively. The procedures were performed with two lumbar incisions and maximally distal resection of the ureters. The two specimens were histologically evaluated by two experienced genitourinary pathologists who found no sign of malignancy. The patient returned to normal life. In March 2015, she was admitted once again for macroscopic haematuria after almost three years without symptoms. Computer tomography showed a solid enhancing mass in the distal region of the right ureteral stump. The patient underwent lower midline laparotomy with resection of the remaining distal ureter with bladder cuff excision (Fig. 1). The same team of pathologists evaluated the specimen and verified it as a high grade urothelial carcinoma of the ureter, according to the 2004 WHO grading system. It was found that the tumour had not invaded the muscle wall, and was verified as pT1 (Fig.e 2). On the first, third and sixth month the patient underwent routine cystoscopies, and no relapse of the disease was observed. On the CT performed in the sixth month no signs of distant metastases were found. 


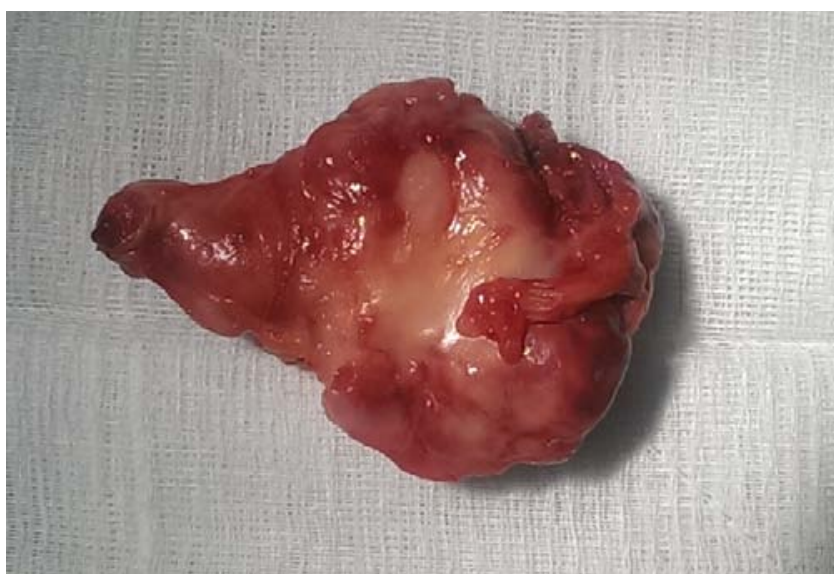

Figure 1. Distal ureter after resection



Figure 2. Distal ureter. Arrowheads show the silk ligature from the native nephrectomy

\section{DISCUSSION}

The presence of de novo cancer in the remnant ureteral stump after nephrectomy for non-malignant reasons is very rare and almost always presents as significant diagnostic problem. Malek et al. reviewed the outcome of the ureteral stump in 4,883 nephrectomies performed for non-malignant disease for 29 years and identified 4 cases of remnant ureteral stump tumour [2]. On the other hand, the renal transplanted population has an at least three times higher risk of developing urothelial carcinoma compared to non-transplanted population [3]. There are series with an incidence of urothelial carcinoma from $0.07 \%$ in a University of California study to $1.9 \%$ in a Beijing group study $[3,4]$.
The higher the incidence in this population is most often associated with immunosuppression. In recent years, there have been studies suggesting an association between polyomaviridae reactivation in immunosuppressed patients triggering its oncogenic potential [5]. Some investigations show that up to $90 \%$ of the human population is infected, but the virus is reactivated only in special cases. Thus, it develops its oncogenic potential via high expression levels of large T-antigen after embedding in the genome.This is the proposed mechanism of oncogenesis, at least in a part of the urothelial neoplasms arising following kidney transplantation [6].

In the presented case, despite the history of macroscopic haematuria, which is an important symptom for the detection of urothelial cancer, it is not an unusual presentation in kidney transplant recipients. Microscopic or macroscopic haematuria is seen in $12 \%$ of patients after kidney transplantation, which is about 15 times higher than that in the general population, especially in patients with ADPKD $[1,7]$. All the previously perforrmed tests and imaging techniques had failed to prove any malignancy. This is how we concluded that the presented case is an example of de novo formation of a urothelial carcinoma in the residual ureter after native bilateral nephrectomy for non-malignant causes in this kidney transplanted patient. After extensive search in the available literature, we also concluded that this is the first published case.

Cases like these must remind the practitioner of the higher risk of malignancy in transplanted patients, and the need for stringent follow-up, even many years after transplantation.

Written informed consent was obtained from the patient who was the subject of this case.

\section{REFERENCES}

1. Fuller TF, Brennan TV, Feng S, Kang S, Stock PG, Freise CE. End stage polycystic kidney disease: indications and timing of native nephrectomy relative to kidney transplantation. J Urol. 2005; 174: 2284.

2. Malek RS, Moghaddam A, Furlow WL, Greene LF. Symptomatic ureteral stumps. J Urol. 1971; 106: 521-528.

3. Master VA, Meng MV, Grossfeld GD, Koppie TM, Hirose R, Carroll PR. Treatment and outcome of invasive bladder cancer in patients after renal transplantation. J Urol. 2004; 171(3): 1085-1088.

4. Li XB, Xing NZ, Wang Y, Hu XP, Yin H, Zhang XD. Transitional cell carcinoma in renal transplant recipients: a single center experience. Int J Urol. 2008; 15(1): 53-57.

5. Alexiev BA, Randhawa P, Vazquez Martul E, Zeng G, et.al. BK virusassociated urinary bladder carcinoma in transplant recipients: report of 2 cases, review of the literature, and proposed pathogenetic model Hum Pathol. 2013 May; 44(5): 908-17. doi: 10.1016/j.humpath.2012.09.019. Epub 2013 Jan 11.

6. Kenan DJ, Mieczkowski PA, Burger-Calderon R, Singh HK, Nickeleit $\mathrm{V}$. The oncogenic potential of BK-polyomavirus is linked to viral integration into the human genome. J Pathol. 2015 Nov; 237(3): 379-89. doi: 10.1002/path.4584. Epub 2015 Aug 19.

7. Previte SR, Murata GT, Olsson CA, Schmitt GW, Nabseth DC, Cho SI. Hematuria in renal transplant recipients. Ann Surg. 1978; 187: 219-22. 